\title{
LIFE HISTORY IN A COPEPOD (LEPTODIAPTOMUS ASHLANDI) FOLLOWING THE INVASION OF LAKE TROUT IN YELLOWSTONE LAKE, WYOMING
}

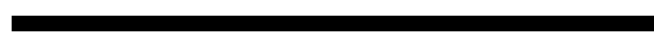

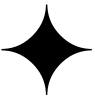 \\ AMY KRIST $\uparrow$ LUSHA TRONSTAD $\uparrow$ HEATHER JULIEN \\ UNIVERSITY OF WYOMING † LARAMIE \\ TODD KOEL \\ CENTER FOR RESOURCES $\downarrow$ YelloWstone NATIONAL PARK
}

\section{$\uparrow \quad$ INTRODUCTION}

Introduced, non-native predators often impact native species and ecosystems. These effects can be particularly devastating to native organisms because they are often naïve to the effects of nonnative predators (Park 2004, Lockwood et al. 2007). Interestingly, naïve prey are more common in freshwater than in terrestrial ecosystems (Cox and Lima 2006). For example, introduced predators in lakes have caused local extinctions of native animals (e.g., Brooks and Dodson 1965, Witte et al. 1992) and altered food webs (e.g., Witte et al. 1992; Tronstad, Hall, Koel, in review). Because predators eliminate a prey's fitness, predation is an important selective force. Selection on prey can occur directly on morphology, behavior and life-history traits by altering the mean expression of a trait in a population. Selection on prey can also act indirectly, favoring phenotypic plasticity which ameliorates the effects of predation. Thus, among the many impacts of non-native predators in their introduced range, these animals can alter the morphology, behavior and life-history traits of their prey (e.g., Reznick and Endler 1982, Crowl and Covich 1990, Skelly and Werner 1990, Krist 2002).

Evolutionary consequences of invasive predators should be widespread because invasive species often alter natural selection on native species (Sakai et al. 2001). When introduced predators select prey based on body size, selection on life-history traits may be altered for one or more organisms in the food web because size-selective predation typically causes mortality rates to differ between adults and juveniles. Size-selective predation is a powerful selective agent on life histories. Many studies have shown shifts in life-history traits from size-specific mortality as a result of fishing and hunting practices (e.g., Coltman, O’Donoghue et al. 2003, Law 2007) and in many natural systems (e.g., Reznick and Endler 1982; Reznick et al. 1990, Fisk et al. 2007).

Assuming that size-selective predation is age-specific, theoretical and empirical work on lifehistory evolution predicts that mortality of large individuals should select for earlier maturity (Stearns and Koella, 1986, Kozlowski and Uchmanski 1987, Kozlowski, Wiegert 1987, Kawecki and Stearns 1993), higher reproductive effort (Gadgil and Bossert 1970, Schaffer 1974, Charlesworth and Leon 1976, Law 1979, Michod 1979, Kozlowski and Uchmanski 1987) and smaller offspring (Reznick and Endler 1982, Reznick et al. 1990). Furthermore, when early maturity occurs at a smaller size, mature adults can have smaller body sizes in species with determinate or asymptotic growth.

Predator-induced phenotypic plasticity is another common consequence of predation. For example, zooplankton in lakes use kairomones to detect potential predators (Dodson 1989b). In 
zooplankton, predator-induced responses can alter morphology, behavior or life-histories traits (Larsson and Dodson 1993, Lass and Spaak 2003) and often protect the animals from predation. For example, within 11 years after the introduction of a sizeselective predator, body size, size at first reproduction, and clutch size of Daphnia spp. and Bosmina longirostris changed relative to preintroduction (Amundsen, Siwertsson, Primicerio, and Bohn, 2009). These traits are likely beneficial to zooplankton in the presence of predators, because they reduce the chance of being consumed. For example, in cladocerans, smaller clutch sizes and a smaller size at first reproduction (which leads to smaller adult body sizes) decreased their visibility to predators (Gliwicz 1981, Latta et al. 2007). Similarly, female Cyclops (Copepoda) carrying large numbers of eggs are more susceptible to predation by planktivorous brook trout (Dawidowicz and Gliwicz 1983). Thus, another possible outcome of the introduction of non-native predators is adaptive (beneficial; sensu Gotthard and Nylin 1995) changes in life-history traits resulting from phenotypic plasticity.

The introduction of predaceous lake trout may have indirectly altered the life histories of zooplankton in Yellowstone Lake, Yellowstone National Park, Wyoming. Non-native lake trout (Salvelinus namaycush) were illegally introduced to Yellowstone Lake (Kaeding et al. 1996) around 1985 (Munro et al. 2005). Following the introduction of this piscivorous fish, which primarily eat native Yellowstone cutthroat trout (Oncorhynchus clarki bouvieri) in Yellowstone Lake (Ruzycki et al. 2003), the abundance of cutthroat trout declined. In fact, cutthroat trout abundance decreased by $60 \%$ in Yellowstone Lake and $99 \%$ in Clear Creek, a spawning stream since 1990 (Koel et al. 2005). Presently indices of cutthroat trout abundance are the lowest in the historical record (Koel et al. 2007). This decline is of grave concern because Yellowstone Lake is the largest remaining stronghold of Yellowstone cutthroat trout (Varley and Gresswell 1988).

The extreme decline in Yellowstone cutthroat trout abundance has severely reduced predation on zooplankton in Yellowstone Lake because a large proportion of the diet of these fish consists of zooplankton. For example, Jones et al., (1990) found that $80 \%$ of the volume of food in cutthroat trout stomachs were zooplankton. Furthermore, Tronstad et al. (in prep) discovered that cutthroat trout ate more zooplankton when these fish were abundant. However, cutthroat trout consumed more benthic invertebrates when these fish were less abundant. Cutthroat trout primarily consume large zooplankton because they are retained in their gill rakers while small individuals pass through uneaten. Longer cutthroat trout have wider inter-gill raker spaces and can filter only larger zooplankton. Thus, cutthroat trout are size-selective predators of zooplankton in Yellowstone Lake. Consequently, after the introduction of lake trout and decline of cutthroat trout, zooplankton in Yellowstone Lake were largely released from size-selective predation. Therefore, after the decline of cutthroat trout, zooplankton should have experienced relaxed selection for life-history traits that were favored by size-selective predation. We addressed whether lifehistory traits differed between pre-lake trout and post-lake trout invasion in Leptodiaptomus ashlandi, the most common copepod species in Yellowstone Lake.

Changes in life-history traits between copepods from before and after the introduction of lake trout could be either genetically based or phenotypically plastic shifts or a combination of both. Genetically based changes are possible because of changes in selection pressure from the recent release of zooplankton from size-selective predation. Plasticity is possible because the number of cutthroat trout releasing cues have changed between the past and recent. For either changes in genotype frequencies or phenotypically plastic traits, sizeselective predation is predicted to lead to a smaller size at first reproduction, larger clutch sizes, and smaller offspring. First, under adult-specific mortality, life-history theory predicts earlier maturity (Stearns and Koella 1986, Kozlowski and Uchmanski 1987, Kozlowski and Wiegert 1987, Kawecki and Stearns 1993). Because copepods do not grow after they become mature (Williamson and Reid 2001), earlier maturity should also lead to a smaller adult size. Likewise, if adaptive plasticity is occurring, smaller size at first reproduction is predicted because smaller cladocerans are less conspicuous to predators (Gliwicz 1981, Latta et al. 2007). Presumably smaller copepods are also less conspicuous to visual predators like cutthroat trout. Second, both selection for genetically based traits and for adaptive phenotypic plasticity predict larger clutch sizes. Under adult-specific mortality, life-history theory predicts higher reproductive effort (Gadgil and Bossert 1970, Schaffer 1974, Charlesworth and Leon 1976, Law 1979, Michod 1979, Kozlowski and Uchmanski 1987). Larger clutch sizes are one metric of greater investment in reproduction. Likewise, with adaptive plasticity, larger clutches are predicted under size-specific predation of large individuals. In 
this case, larger clutch sizes are a side effect of small size at maturity. In cladocerans, small Daphnia produce smaller offspring (Lampert 1993). Assuming a trade-off between number and size of offspring (Stearns 1992), organisms producing smaller offspring make more of them. Finally, several empirical studies have shown that selection by adult-specific mortality leads to smaller offspring (Reznick and Endler 1982, Reznick et al. 1990). These differences persist in common environments, so they are the result of evolved changes in trait means among populations rather than adaptive plasticity. As discussed above, phenotypic plasticity resulting from size-selective predation also can lead to smaller offspring.

To examine these predictions, we compared size of reproducing individuals, clutch size, and egg size of $L$. ashlandi copepods that were collected before the introduction of lake trout with recent samples collected after the decline of cutthroat trout. Because copepods do not grow after maturity (Williamson and Reid 2001), the size of reproducing individuals indicates the size at first reproduction. We did not examine body size because size-selective predation on large individuals in the past resulted in a smaller mean size in the samples. Conversely, release from size-selective predation led to larger mean individual size in the recent samples. Hence, any changes due to possible evolutionary shifts or phenotypic plasticity in body size are not detectable with these data.

\section{$\uparrow \quad$ METHODS}

\section{Study ecosystem}

Yellowstone Lake is on the Yellowstone Plateau in Wyoming and is the largest high-elevation (2,357 m) lake in North America (Gresswell, Liss, Larson, and Bartlein, 1997), with a surface area of $341 \mathrm{~km}^{2}$, shoreline length of $239 \mathrm{~km}$, and average depth of $43 \mathrm{~m}$ (Kaplinksi 1991). Yellowstone Lake is mesotrophic (Kilham, Theriot, and Fritz, 1996) and is ice-covered from December through May (Gresswell and Varley, 1988).

In Yellowstone Lake, there are only a few species of plankton. Phytoplankton are dominated by diatoms (Stephanodiscus spp., Cyclotella bodanica, Aulacoseira subarctica, and Asterionella formosa; Interlandi et al. 1999). The crustacean zooplankton in Yellowstone Lake consist of 3 species of copepods (Diacyclops bicuspidatus thomasi, Leptodiaptomus ashlandi, and Hesperodiaptomus shoshone) and 2 species of cladocerans (Daphnia schфdleri and D. pulicaria). We chose to study L. ashlandi, because this species is much more abundant than the other copepods. Also, for both past and present samples, we had an adequate number of reproducing individuals that we could analyze for total length, number of eggs, and egg size. We did not measure the response of cladocerans because previous preservation methods may have caused eggs to be expelled from the brood chamber (Prepas 1978).

The fish assemblage in Yellowstone Lake includes 2 native species and 1 dominate non-native species. Yellowstone cutthroat trout and the less abundant longnose dace (Rhinichthys cataractae; Gresswell et al. 1997) are native to Yellowstone Lake. Juvenile cutthroat trout in Yellowstone Lake are thought to be pelagic and feed on zooplankton, whereas adult fish (>325-mm total length) consume both benthic macroinvertebrates and zooplankton (Benson 1961). Lake trout were illegally introduced into Yellowstone Lake in about 1985 (Munro et al. 2005) and cutthroat trout are the main food of these invasive predators (Ruzycki et al. 2003).

The cutthroat trout population in Yellowstone Lake faces several threats. Based on bioenergetics modeling, predation by lake trout is a serious threat to native cutthroat trout in Yellowstone Lake (Ruzycki et al. 2003). Also, Myxobolus cerebralis, the parasite that causes whirling disease, was discovered in Yellowstone Lake in 1998 and mainly affects young-of-the-year cutthroat trout in certain spawning streams (Koel et al. 2006). Recent drought also affects young-of-the-year cutthroat trout in small tributary streams by stranding individuals (Koel et al. 2005). However, because the decline of cutthroat trout is widespread, most of the loss has been attributed to lake trout predation.

\section{Sample collection}

We borrowed zooplankton samples from Yellowstone National Park from 1976-1981 to analyze the characteristics of copepods prior to the invasion of lake trout. These samples from the past were collected during the ice-free season at 4 locations in Yellowstone Lake (east of Stevenson Island, West Thumb, South East Arm, and South Arm; Figure 1). Zooplankton were collected by the U.S. Fish and Wildlife Service using 20-m, vertical hauls with a plankton net $(80-\mu \mathrm{m}$ mesh size) between 23 May and 19 October 1976-1981. Past samples were preserved in formalin. 


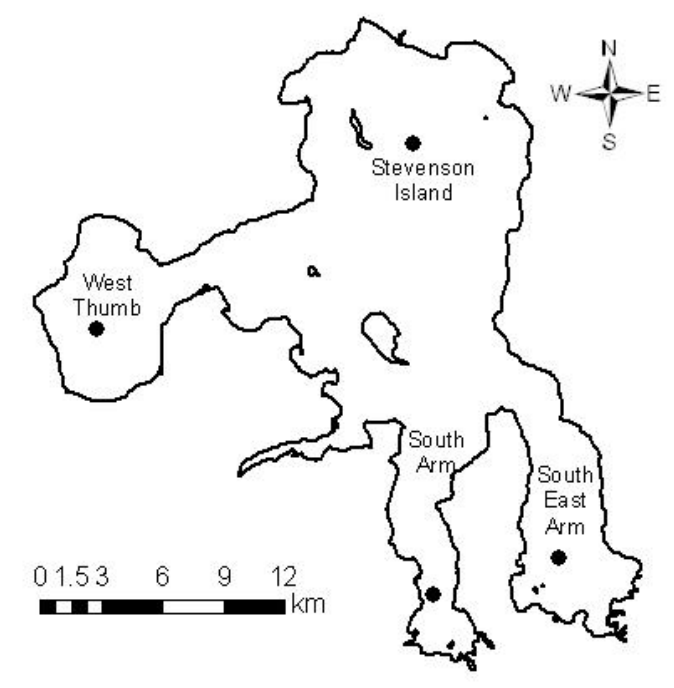

Figure 1. Map of Yellowstone Lake showing the 4 collection sites (closed circles).

For our recent (2004) samples, we collected 2 samples on 9 dates between 21 May and 19 October (the ice-free season) at the same 4 locations in Yellowstone Lake (east of Stevenson Island, West Thumb, South East Arm, and South Arm). We collected zooplankton using the same procedures and nets that were used to collect the samples from the past. Zooplankton samples were preserved in cold sugared formalin. We enumerated and measured past and recent zooplankton samples under a dissecting microscope.

\section{Sample analysis}

We collected two separate sets of data to address our questions. For the first data set, we measured all individuals to assess the probability of reproducing. For each individual, we measured the total body length (length of prosome and urosome) of all individuals in a subsample and recorded whether or not the individual was carrying an egg sac. The second data set included only individuals that were reproducing. This dataset was used to assess the clutch size and egg size. For this dataset, we arbitrarily analyzed 43 of the 72 recent samples and all of the past samples. We searched whole samples for reproductive females and analyzed up to 10 individuals with egg sacs. For each female with a clutch of eggs, we measured body length (length of prosome because the clutch of eggs obscured the urosome from the ventral side), counted the number of eggs in an egg sac, and measured the diameter of 5 haphazardly selected eggs. For both sets of data, we measured length using an ocular micrometer on a dissecting microscope.

\section{Data analysis}

For all analyses, sample sizes were larger in 2004. For clutch size and egg size, there were 43 reproductive individuals from the past and 220 in the recent samples. To determine the variables that predicted clutch size and egg size of L. ashlandi copepods, we used multiple regression analysis to compare samples from the past $(1976,1977,1981)$ with samples from 2004. To increase the homogeneity of variances between past and recent samples, we log transformed the values of individual clutch size. To determine the variables that predicted reproductive status, we used logistic regression analysis to compare past (1977- 1980) and recent (2004) samples. Because we have fewer samples from the past and characteristics of zooplankton among years were similar (Tronstad et al. in press), we analyzed all of the past samples together (combined years).

To select models for multiple and logistic regression analyses, we developed a set of a priori candidate models that included all of the potentially relevant effects and all likely causal mechanisms (Burnham and Anderson 2002). By comparing the candidate models using Akaike's information criteria (AIC), we chose the best models based on the lowest AIC value. Our candidate models included time (past vs. recent), body length, water temperature, Secchi disk depth, collection site, and day length. Because both egg size and the number of eggs per sac can vary by season in copepods (Hutchinson, 1951; Elbourn 1966, Kerfoot 1974), we included temperature and day length in the candidate models. Secchi disk depths were included as a proxy for phytoplankton concentrations because phytoplankton samples were rarely collected in the past. However, Secchi disk depth is negatively correlated with chlorophyll $a$ levels $(\mu \mathrm{g} / \mathrm{L})$ in the water column $\left(\mathrm{r}^{2}=\right.$ $0.44, \mathrm{p}<0.0001$ ) and can be used as an index of phytoplankton biomass (Tronstad et al., in press). We included the site where the samples were collected because currently West Thumb has the highest density of lake trout (Koel et al. 2005) and the South Arm site is believed to be a refuge for Yellowstone cutthroat trout (Koel et al. 2003). Although samples were collected from four sites for both time periods, we only included three sites (South Arm, Stevenson Island, and West Thumb) in our analyses because at one site (South East Arm) Secchi disk depths were strongly affected by inputs from the Yellowstone River and hence were not proxies of phytoplankton 
biomass (Theriot et al.1997). For all analyses, South Arm was the reference site. We included a time by site interaction in some of our candidate models because differences in lake trout densities among sites did not occur in the past before lake trout were introduced. For the models predicting measures of fecundity and reproductive status, we also included a time by body length interaction among the candidate models. A significant time by body length interaction is possible, because natural selection could alter the relationship between fecundity and body length between past and recent copepods.

\section{$\uparrow \quad$ RESUlTS}

\section{Clutch size}

Mean clutch sizes differed between the past and the present; the mean number of eggs per sac was 11.4 in the past and 22.9 egg in the recent samples. However, the multiple regression model of $\ln$ of clutch size indicates that the differences in clutch size are not predicted by time (the date the samples were collected) but rather by body length, day length, Secchi disk depth, and site of collection (Table 1a). Each of these variables differed between past and recent samples. The average body length of copepods was smaller in the past (past: $1.4 \mathrm{~mm}$, recent: 1.7 $\mathrm{mm}$; Figure 2) because size-selective predation of large copepods was very common when cutthroat trout were abundant. The average number of daylight hours differed between the two sampling times (past $=14.30 \mathrm{hr}$., recent $=15.06 \mathrm{hr}$.) as a result of uneven sampling of seasons between the two sampling periods. Average Secchi disk depth, an indicator of phytoplankton biomass (Tronstad et al. in press), were deeper in 2004 (past $=7.23 \mathrm{~m}$, recent $=7.71 \mathrm{~m}$ ) indicating lower phytoplankton biomass in recent time.

Of these variables that affected the total number of eggs produced by copepods, body size had the largest effect. For every millimeter increase in the length of the copepod, the total number of eggs in the clutch increased by about 4 eggs. The number of daylight hours when the sample was collected had the second greatest effect on clutch size. For every hour increase in day length, clutch size increased by 1.5 eggs. Also, for every meter increase in Secchi disk depth, the clutch size decreased by about 1 egg. Finally, clutch sizes differed among collection sites; copepods collected from West Thumb had fewer eggs per clutch than at South Arm (reference site). For an average-sized clutch in the past (11.4 eggs), the predicted clutch size is $6 \%$ lower for West Thumb than for South Arm. The predicted clutch size is 3\% lower at West Thumb than for South Arm for an average-sized clutch in recent time (22.9 eggs). This difference is particularly interesting because within Yellowstone Lake, the South Arm area is considered a refuge for Yellowstone cutthroat trout and the West Thumb region has the highest density of lake trout. The significant time by site interaction indicates that clutch sizes differed over time between the West Thumb and South Arm sites (Table 1A).

Table 1. Multiple regression tables for A.) clutch size and B.) egg size for L. ashlandi copepods. Values of clutch size were natural log transformed. For both analyses, past is the reference category for time and South Arm is the reference category for collection site.

\section{A. Clutch size}

\begin{tabular}{lllll}
\hline & $\begin{array}{l}\text { Estimat } \\
\text { ed Std }\end{array}$ & Error & t-value & $P$-value \\
\hline Intercept* & -4.73 & 0.68 & -6.91 & $<0.0001$ \\
Time-recent & 0.03 & 0.15 & 0.20 & 0.845 \\
Body length* & 1.34 & 0.23 & 5.90 & $<0.0001$ \\
Temperature & -0.02 & 0.01 & -1.34 & 0.182 \\
$\begin{array}{l}\text { Stevenson Island } \\
\text { West Thumb* }\end{array}$ & -0.46 & 0.29 & -1.60 & 0.115 \\
$\begin{array}{l}\text { Secchi disk } \\
\text { depth* }\end{array}$ & -0.39 & 0.20 & -1.99 & 0.048 \\
$\begin{array}{l}\text { Daylight* } \\
\text { Recent x }\end{array}$ & 0.42 & 0.03 & -2.97 & 0.003 \\
$\begin{array}{l}\text { Stevenson Island } \\
\text { Recent x West }\end{array}$ & 0.32 & 0.32 & 8.18 & $<0.0001$ \\
Thumb* & 0.60 & 0.20 & 3.10 & 0.319 \\
\hline
\end{tabular}

B. Egg size

\begin{tabular}{|c|c|c|c|c|}
\hline & $\begin{array}{l}\text { Estimated } \\
\text { Std }\end{array}$ & Error & t-value & $P$-value \\
\hline Intercept* & 0.067 & 0.0072 & 9.29 & $<0.0001$ \\
\hline $\begin{array}{l}\text { Time- } \\
\text { recent* }\end{array}$ & 0.016 & 0.0011 & 14.86 & $<0.0001$ \\
\hline Body length & 0.00089 & 0.0023 & 0.38 & 0.702 \\
\hline Temperature & 0.00014 & 0.0001 & 1.01 & 0.314 \\
\hline $\begin{array}{l}\text { Secchi disk } \\
\text { depth }\end{array}$ & -0.00046 & 0.0003 & -1.62 & 0.107 \\
\hline $\begin{array}{l}\text { Stevenson } \\
\text { Island }\end{array}$ & 0.00079 & 0.0008 & 0.95 & 0.344 \\
\hline $\begin{array}{l}\text { West } \\
\text { Thumb* }\end{array}$ & 0.0039 & 0.0010 & 3.84 & 0.0002 \\
\hline Daylight & 0.00066 & 0.0005 & 1.27 & 0.205 \\
\hline
\end{tabular}

Egg size

Egg sizes were significantly smaller in the past. For an average-sized copepod $(1.62 \mathrm{~mm})$, the multiple regression model predicted that egg size was $21.6 \%$ higher in recent than in past samples (Figure $3)$. Collection site was the only other significant predictor of egg size (Table 1B). Similar to clutch size, egg sizes were significantly larger at West Thumb than South Arm. For an average-sized egg in 
the past $(0.077 \mathrm{~mm})$, the predicted egg size is $5 \%$ higher for West Thumb than for South Arm. The predicted egg size is $4 \%$ higher for an average-sized egg in recent time $(0.94 \mathrm{~mm})$ at West Thumb than South Arm.

\section{Reproductive status}

Body length was the strongest predictor of whether or not a copepod was reproducing. With increased body size, the probability of reproducing in copepods increased steeply after copepods achieved a minimum size (Figure 4). The minimum size at which copepods were reproducing was smaller in the past (Figure 4; significant effect of time in Table 2). For a probability of reproducing of 0.15 , the predicted size of a reproductive copepod is $\sim 10 \%$ higher in the present than in the past. Also, for any given sized copepod, the probability of reproducing was 2.6 times higher for copepods in the past than in the present (odds ratio, $\mathrm{w}_{\text {present }} / \mathrm{w}_{\text {past }}=0.39$ ). The probability of reproducing also increased with shorter day lengths and shallower Secchi disk depth (an indicator of higher phytoplankton biomass) suggesting a seasonal effect on reproductive status. However, temperature did not significantly affect reproductive status. Finally, the probability of reproducing did not differ between South Arm and the other sites (Table 2).

Table 2. Logistic regression analysis for the probability of reproducing. Past is the reference category for time and South Arm is the reference category for collection site.

\begin{tabular}{lllll} 
& $\begin{array}{l}\text { Estimated } \\
\text { Std }\end{array}$ & Error & t-value & $P$-value \\
\hline Intercept* $^{*}$ & -5.04 & 1.68 & -3.01 & 0.003 \\
Time-recent* $^{*}$ & -0.93 & 0.32 & -2.92 & 0.003 \\
Body length* & 7.27 & 0.61 & 11.87 & $<0.0001$ \\
$\begin{array}{l}\text { Stevenson } \\
\text { Island }\end{array}$ & -0.41 & 0.26 & -1.57 & 0.116 \\
West Thumb & -0.43 & 0.36 & -1.20 & 0.229 \\
Temperature & 0.04 & 0.03 & 1.28 & 0.201 \\
$\begin{array}{l}\text { Secchi disk } \\
\text { depth* }\end{array}$ & -0.22 & 0.10 & -2.25 & 0.024 \\
Daylight* & -0.33 & 0.10 & -3.43 & 0.0006 \\
\hline
\end{tabular}

\section{$\downarrow$ DISCUSSION}

Both size at first reproduction and egg size of L. ashlandi were smaller in the past (1976 - 1981) compared to recent (2004) zooplankton samples. These differences in life-history traits are consistent with rapid evolution, as predicted by life-history theory. If these copepods can differentiate between the cues from planktivorous and non-planktivorous fish, these differences may also be the result of adaptive plasticity in response to cues from planktivorous fish that have decreased over time.

Our results are consistent with rapid evolution of life-history traits in response to agespecific mortality. In Yellowstone Lake, age-specific mortality occurred in the past when Yellowstone cutthroat trout were abundant. These trout primarily consume large zooplankton because they are retained in their gill rakers while small individuals pass through the gill rakers uneaten (Tronstad et al., in review). The introduction of piscivorous lake trout in Yellowstone Lake resulted in a $60 \%$ reduction in Yellowstone cutthroat trout and fewer individuals in the size classes that can consume L. ashlandi (Tronstad et al., in review). This large reduction of cutthroat trout caused a large change in selection on copepod life-history traits. In a relatively short period of time, L. ashlandi experienced a change from high adult-specific mortality to very little mortality.

Life-history theory predicts that age-specific mortality should favor individuals that mature early and have a greater investment in reproduction (Gadgil and Bossert 1970, Law 1979, Michod 1979). Because copepods from the past experienced strong age-specific mortality, we predicted that they would mature earlier and invest more in reproduction than copepods from recent samples. We found that copepods matured at a smaller size in the past than in recent time (Figure 4). Size at first reproduction is a good proxy for age at first reproduction assuming individuals that mature early also mature at a smaller size. However, we did not find evidence that copepods invested more in reproduction in the past. In addition, empirical life-history studies have shown that small offspring result from adult-specific mortality (e.g., Reznick and Endler 1982, Reznick et al. 1990). Consistent with these studies, we found that egg sizes were smaller in the past.

Our results are also consistent with adaptive phenotypic plasticity. For example, cladocerans can adjust their life-history traits in response to cues from planktivorous fish (Larsson and Dodson 1993). Several species of cladocerans mature at a smaller size in the presence of fish (Stibor 1992, Vonderbrink and Vanni 1993, Weber and Declerck 1997), as an effective way to reproduce before they achieve a size that is vulnerable to size-specific predation (Dodson 1989a). Size-selective predation of large individuals by planktivorous fish can also induce the production of many, small eggs in cladocerans (Dodson 1989b; Stibor 1992). This plasticity is also thought to be adaptive because smaller eggs produce smaller 


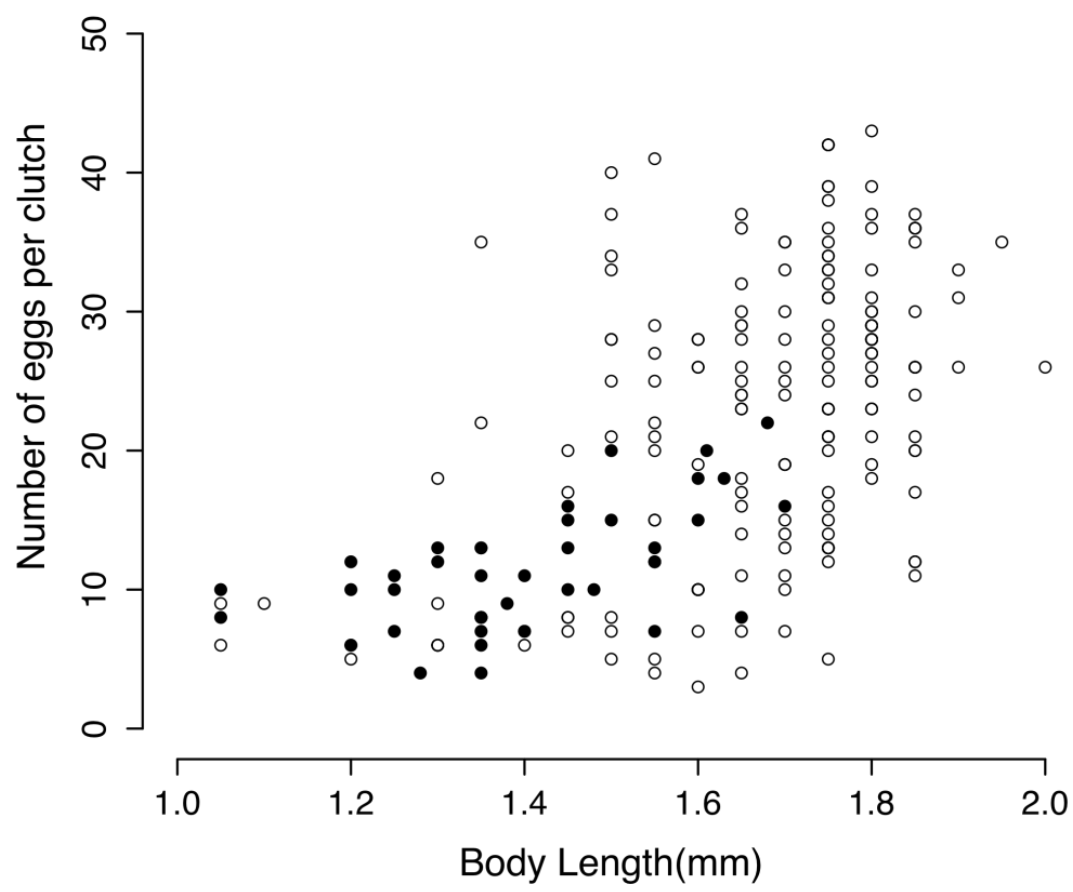

Figure 2. The number of eggs per clutch as a function of body length of $L$. ashlandi copepods. Note that in the multiple regression analysis (Table 1A), clutch size is natural log transformed. Filled circles are clutch sizes from the past $(1976,1977,1981)$ and open circles are from 2004

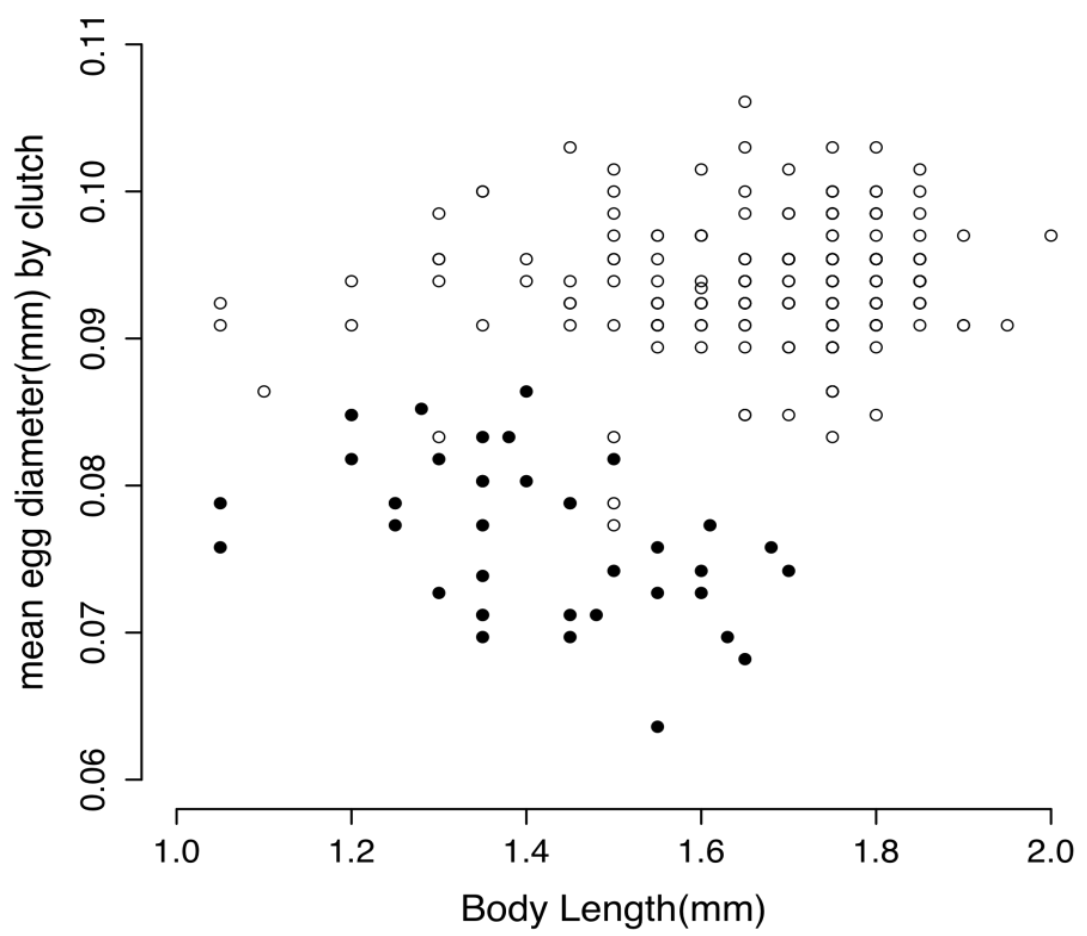

Figure 3. Mean egg size per clutch as a function of body length of $L$. ashlandi copepods. Filled circles are clutch sizes from the past $(1976,1977,1981)$ and open circles are from 2004. 


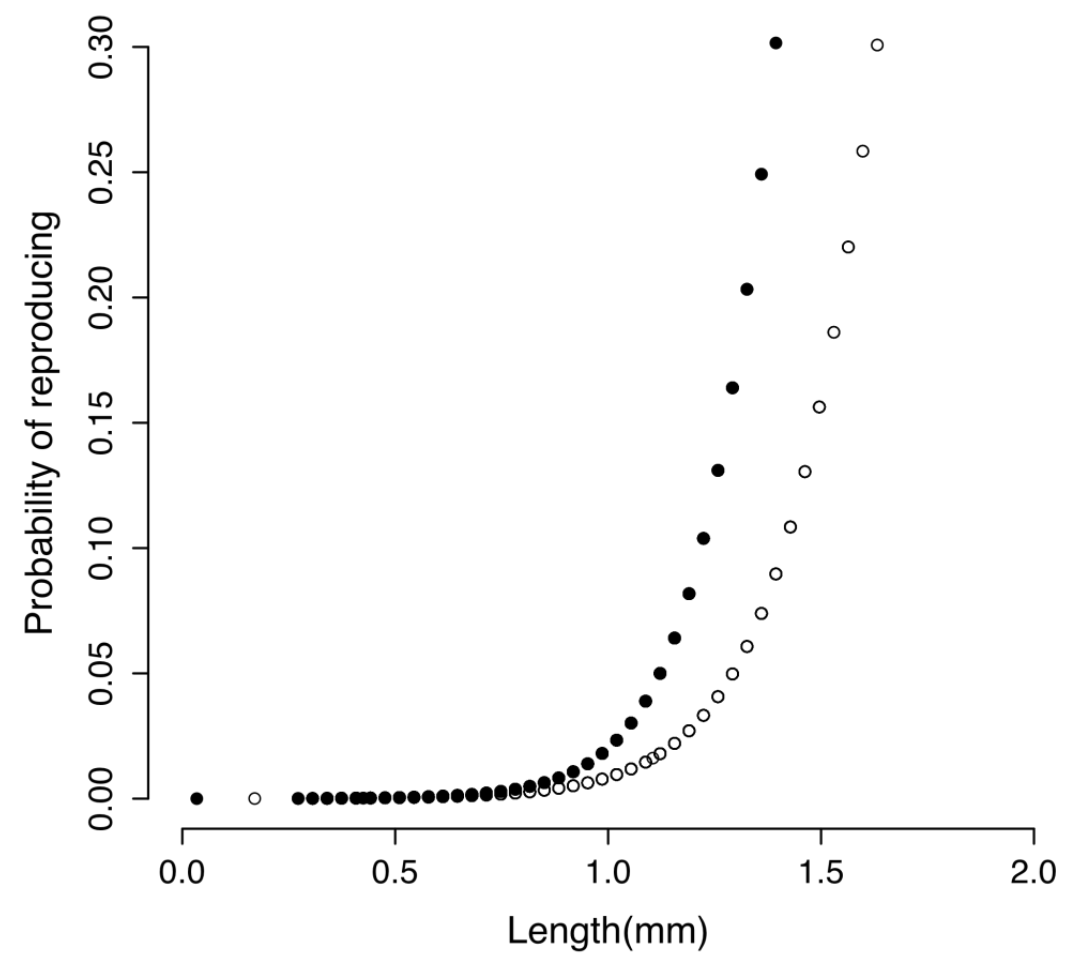

Figure. 4. Probability of reproducing for past (closed circles; 1977-1980) and recent (open circles; 2004) L. ashlandi copepods. Expected values are the fitted line for the logistic regression

offspring which mature at smaller sizes (Ebert et al. 1993, Lampert 1993). In addition, we are aware of one study showing predator-induced life-history changes in calanoid copepods (Gutierrez et al. 2010). Also, copepods exhibit predator-induced defenses in swimming behavior (Ramcharan and Sprules 1991), and vertical migration (Ohman et al. 1983, Bollens and Frost 1989, Neill 1990). These studies suggest that some copepods can respond to predator cues, and consequently, that predator-induced shifts in lifehistory traits are likely in copepods.

The forms of adaptive phenotypic plasticity described above are a type of inducible defense because all of the life-history shifts increase individual fitness. Inducible defenses are predicted to evolve under four conditions: 1) the defense is beneficial, 2) there are reliable cues indicating the future risk of attack, 3) the threat is variable or unpredictable, and 4) the defense is costly to maintain, otherwise a constitutive defense would be favored by evolution (Tollrian and Harvell 1998). In our system, these conditions are probably met. First, the shifts in life-history traits are beneficial because they increase fitness. If copepods are able to distinguish between the cues of cutthroat trout and lake trout then cues are likely to be reliable indicators of future risk of predation because induced defenses in copepods can be predator-specific (Ohman et al. 1983). Second, because cutthroat trout have lived in Yellowstone Lake for thousands of years (Behnke 2002), the presence of these fish is likely a reliable cue of the threat of predation. Third, the threat of predation is variable. The number of spawning cutthroat trout has varied dramatically over the past 65 years (Koel et al. 2005). Over time, the variability was caused by collecting eggs from spawning cutthroat trout, changing angler regulations, and recently, by the introduction of lake trout. Finally, under certain environmental conditions, some of these life-history traits may also be costly. For example, when resources are limited, small offspring can have lower survival because of lower energy reserves (J. Jokela, unpublished data on juvenile New Zealand mud snails). If these conditions are usually met in this ecosystem, then phenotypic plasticity is a likely explanation for the observed patterns in lifehistory traits between the past and present samples. 
In contrast to predictions, clutch sizes did not differ in $L$. ashlandi between past and recent samples in Yellowstone Lake. Differences in mean clutch sizes were attributable to differences in body size, day length and phytoplankton biomass (as estimated by Secchi disk depths). First, perhaps the discrepancy between observed and predicted clutch sizes results from greater food availability in 2004 (higher density of small phytoplankton $<30 \mu \mathrm{m}$ greatest axial linear dimension despite lower phytoplankton biomass overall; Tronstad et al. in review). With greater resources, clutch sizes of copepods can be larger (Hart 1996). Second, we may not have found differences in clutch sizes between past and recent samples because we have data from a variety of clutches from different-aged copepods. In copepods, clutch size tends to decrease with age (Smyly 1970, Devreker et al. 2009). Third, cutthroat trout may act as an opposing force of selection for decreased clutch sizes if larger clutch sizes increase the visibility of $L$. ashlandi to these visual predators. For example, copepods with larger clutch sizes suffer higher mortality from brook trout because of their increased visibility (Dawidowicz and Gliwicz 1983). The same phenomenon occurs in cladocerans with visually-feeding planktivorous fish (Mellors 1975, Gliwicz 1981, Latta et al. 2007). Hence, clutch size may be experiencing opposing forces. Size-selective predation on adult copepods favors large clutches, but visually-feeding predators should favor lower clutch sizes. These opposing forces may be why we see no difference in clutch sizes between past and recent samples. In contrast, the forces shaping size at maturity are congruent. Size-selective predation of large copepods favors a smaller size at first reproduction and small size at maturity reduces visibility and increases survival in the presence of visually-feeding predators (Latta et al. 2007). Hence, it is not surprising that copepods were smaller in the past under size-selective predation by a visually feeding predator. Finally, differences in clutch size could be explained by size-selective predation. Since both cladocerans and copepods with large clutch sizes are more visible to predators (Gliwicz 1981, Dawidowicz and Gliwicz 1983), mean clutch sizes are predicted to decrease as individuals with large clutches are more likely to be eaten by planktivorous fish. Therefore, perhaps clutch sizes were in fact larger in the past, but we did not observe a difference because many of the large clutches had already been consumed when the copepods were collected.

In addition to the differences that we observed between past and recent copepods, we also found life-history shifts between sites that are consistent with either adaptive plasticity or rapid evolution. Both egg size and clutch size differed between West Thumb and South Arm. South Arm of Yellowstone Lake is a refuge for Yellowstone cutthroat trout (Koel et al. 2003) and West Thumb is where the highest density of lake trout occur (Koel et al. 2005). Therefore, as a result of either rapid evolution or adaptive plasticity, egg sizes are predicted to be lower and clutch sizes higher at South Arm where Yellowstone cutthroat trout are causing higher size-selective predation on adult $L$. ashlandi. Consistent with these predictions, egg sizes were significantly smaller (3\%) and clutch sizes were significantly larger (4\%) in current samples from South Arm than in West Thumb. These two sites are over $27 \mathrm{~km}$ apart, so these differences could be the result of adaptive phenotypic plasticity or local adaptation if movement and dispersal distances of $L$. ashlandi are less than $27 \mathrm{~km}$. Therefore, we have evidence for beneficial changes in life-history traits over time and space.

Changes in life-history traits in past and recent copepods may result from either rapid evolution of genotype frequencies or adaptive phenotypic plasticity. The elapsed time since the introduction of lake trout is likely sufficient for evolutionary changes. There was 19 years for evolutionary changes to occur between the introduction of lake trout $(\sim 1985)$ and the recent samples (2004). Given that freshwater copepods live for one to several months (Williamson and Reid 2001), there are 2-4 generations of copepods per year or 38-76 generations between the past and recent samples. Also, rapid evolution of timing of diapause in another calanoid copepod occurred in only 4 years (Hairston and Walton 1986) suggesting that with ample selection pressure, 19 years is sufficient for evolutionary change to occur. Gene flow among lakes is also likely to be quite small in these aquatic animals. Additionally, shifts in life-history traits may be the result of adaptive phenotypic plasticity. As discussed above, the conditions for the evolution of inducible defenses in this ecosystem are likely to be met. However, in order for adaptive plasticity to explain temporal and spatial differences in $L$. ashlandi life-history traits, these copepods must be able to distinguish between kairomones produced by cutthroat trout and lake trout. If $L$. ashlandi cannot distinguish between the kairomones, then the total amount of trout kairomone may not have changed significantly over time because cutthroat trout declined in abundance but lake trout increased. However, if $L$. ashlandi can distinguish between these kairomones than they could detect the large decrease in the abundance of cutthroat trout over time 
and alter their plasticity in response. To our knowledge it is not known whether freshwater copepods can distinguish between cues from planktivorous and non-planktivorous fish. Because cutthroat trout and lake trout are in the same family (Salmonidae), their kairomones may be too similar to be distinguished. Cladocerans may be able to distinguish between planktivorous and nonplanktivorous fish. Life-history traits of Daphnia responded differently to two fish species (perch and stickleback) in a laboratory experiment, indicating that Daphnia were able to differentiate between fishes (Weber 1999 as cited in Lass and Spaak 2003). In contrast, one study showed that the kairomones released by 3 fish species all exhibited the same chemical characteristics (von Elert and Loose 1996) and another study showed behavioral responses in $D$. magna were induced by both planktivorous and nonplanktivorous fish (Loose, Vonelert, and Dawidowicz 1993). Therefore, whether zooplankton can differentiate between potential fish predators and other fish remains unclear. If copepods cannot distinguish between kairomones from cutthroat trout and lake trout then the shifts in life-history traits that we observed are probably not explained by adaptive phenotypic plasticity.

Life-history traits of $L$. ashlandi were also affected by phytoplankton biomass and the amount of daylight. Our results showed that $L$. ashlandi had larger clutches at shallower Secchi disk depths (higher phytoplankton biomass) and longer daylight hours. Similarly, clutch sizes tended to be larger when more food was available for 3 different species of copepods (Woodward and White 1981, Hart 1996). Additionally, among seasons clutch size of copepods was smallest during summer, when phytoplankton levels were lower than in spring or fall (Hutchinson 1951, Elbourn 1966). Higher food concentrations also increased the egg production rate (eggs per female ${ }^{-1}$ day $^{-1}$ ) in calanoid copepods in laboratory experiments (Hart 1996). In Yellowstone Lake, copepods were also more likely to reproduce at shallower Secchi disk depths (higher phytoplankton biomass) and with fewer hours of daylight. In contrast to our results, female cyclops copepods were more likely to be carrying eggs with greater day lengths (Elbourn 1966). Thus, abiotic factors cause seasonal difference in life-history traits of copepods.

There are two possible alternative explanations for the shifts in life-history traits of copepods that we observed. First, the zooplankton assemblage changed from being dominated by small copepods in the past to being dominated by cladocerans in 2004. Because there were slightly fewer L. ashlandi in 2004, they may have experienced reduced intraspecific competition and perhaps higher growth rates resulting in a larger size at maturity and more eggs. However, cladocerans typically dominate the zooplankton assemblage in lakes with 2 and 4 trophic levels, because cladocerans out compete copepods for food (Brooks and Dodson, 1965). Therefore, we do not expect growth rates of copepods to be higher in recent times. Second, climate change may have altered the zooplankton assemblage in Yellowstone Lake. Water temperatures in Yellowstone Lake have increased by $0.29^{\circ} \mathrm{C} /$ decade (Tronstad et al., in press). In Lake Washington, Washington, USA, water temperatures increased $0.35^{\circ} \mathrm{C} /$ decade (March - June) causing a mismatch between the phytoplankton and Daphnia blooms (Winder and Schindler 2004). As a result, Daphnia densities declined and juvenile mortality increased because of low food resources. However, in Yellowstone Lake Daphnia densities and size have increased (Tronstad et al., in review). Also in copepods, female body size generally decreases with increasing temperatures (Williamson and Reid, 2001). This is inconsistent with our finding that size of reproductive females increased over time as mean temperature increased. Thus, changes in life-history traits of copepods and the zooplankton assemblage in Yellowstone Lake are more likely a result of reduced size-selective predation than intraspecific competition or climate change.

We observed that size at first reproduction and offspring size increased in L. ashlandi copepods collected 19 years after the introduction of lake trout compared to copepods collected prior to the invasion. These shifts in life histories are consistent with both life-history theory, which predicts shifts in genotype frequencies, and with adaptive phenotypic plasticity. Based on our results, it is not possible to assess the relative contributions of changes in genotype frequencies and adaptive phenotypic plasticity. However, adaptive phenotypic plasticity is only likely if $L$. ashlandi can distinguish between the cues of cutthroat trout and lake trout. If these results are attributable to changes in genotype frequencies, then the life-history traits of $L$. ashlandi evolved rapidly ( 19 years) in an indirect response to an invasive predator.

\section{$\downarrow \quad$ Literature Cited}

Amundsen PA, Siwertsson A, Primicerio R, Bohn T. 2009. Long-term responses of zooplankton to invasion by a planktivorous fish in a subarctic watercourse. Freshwater Biology 54:24-34. 
Behnke R.J. 2002. Trout and Salmon of North America. New York: Free Press,.

Benson NG. 1961. Limnology of Yellowstone Lake in relation to the cutthroat trout. U.S. Government Printing Office O-595956.

Bollens SM, Frost BW. 1989. Predator-induced diel vertical migration in a planktonic copepod. Journal of Plankton Research 11:1047-1065.

Brooks JL, Dodson SI. 1965. Predation, body size, and composition of plankton. Science 150: 28-35.

Burnham KP, Anderson DR. 2002. Model Selection and Multimodel Inference. New York: Springer-Verlag.

Charlesworth B, Leon JA. 1976. Relation of reproductive effort to age. American Naturalist 110:449-459.

Coltman DW, O'Donoghue P, Jorgenson JT, Hogg JT, Strobeck C, Festa-Blanchet M. 2003. Undesirable evolutionary consequences of trophy hunting. Nature 426:655-658.

Cox JG, Lima, SL. 2006. Naivete and an aquaticterrestrial dichotomy in the effects of introduced predators. Trends in Ecology \& Evolution 21:674-680.

Crowl TA, Covich AP. 1990. Predator-induced lifehistory shifts in a fresh-water snail. Science 247:949-951.

Dawidowicz P, Gliwicz ZM. 1983. Food of brook charr in extreme oligotrophic conditions of an alpine lake. Environmental Biology of Fishes 8:55-60.

Devreker D, Souissi S, Winkler G, Forget-Leray J, Leboulenger F. 2009. Effects of salinity, temperature and individual variability on the reproduction of Eurytemora affinis (Copepoda; Calanoida) from the Seine Estuary: a laboratory study. Journal of Experimental Marine Biology and Ecology, $368: 113-123$

Dodson SI. 1989a. Predator-induced reaction norms: cyclic changes in shape and size can be protective. Bioscience 39:447-452.
Dodson SI. 1989b. The ecological role of chemical stimuli for the zooplankton - predatorinduced morphology in Daphnia. Oecologia 78:361-367.

Ebert D, Yampolsky L, Vannoordwijk AJ. 1993. Genetics of life-history in Daphnia magna 2: phenotypic plasticity. Heredity 70:344352.

Elbourn CA. 1966. Life cycle of cyclops Strenuus strenuus Fischer in a small pond. Journal of Animal Ecology 35: 333.

Fisk DL, Latta LC, Knapp RA, Pfrender ME. 2007. Rapid evolution in response to introduced predators I: rates and patterns of morphological and life-history trait divergence. Evolutionary Biology 7.

Gadgil M, Bossert, WH. 1970. Life historical consequences of natural selection. American Naturalist 104:1-24.

Gliwicz ZM. 1981. Food and predation in limiting clutch size of cladocerans. Verhandlungen der Internationalen Vereinigung fur Theoretische und Angewandte Limnologie. 21:1562-1566.

Gotthard K, Nylin S. 1995. Adaptive plasticity and plasticity as an adaptation: a selective review of plasticity in animal morphology and life-history. OIKOS 74:3-17.

Gresswell RE, Liss WJ, Larson GL, Bartlein PJ. 1997. Influence of basin-scale physical variables on life history characteristics of cutthroat trout in Yellowstone Lake. North American Journal of Fisheries Management, 17:1046-1064.

Gresswell RE, Varley JD. 1988. Effects of a century of human influence on the cutthroat trout of Yellowstone Lake. American Fisheries Society Symposium 4:45-52.

Gutierrez MF, Paggi JC, Gagneten AM. 2010. Fish kairomones alter life cycle and growth of a calanoid copepod. Journal of Plankton Research 32:47-55.

Hairston NG, Walton WE. 1986. Rapid evolution of a life-history trait. Proceedings of the National Academy of Sciences of the United States of America, 83:4831-4833. 
Hart RC. 1996. Naupliar and copepodite growth and survival of two freshwater calanoids at various food levels: demographic contrasts, similarities, and food needs. Limnology and Oceanography 41:648-658.

Hutchinson GE 1951. Copepodology for the ornithologist. Ecology 32:571-577.

Interlandi SJ, Kilham SS, Theriot EC. 1999. Responses of phytoplankton to varied resource availability in large lakes of the Greater Yellowstone Ecosystem. Limnology and Oceanography 44:668-682.

Jones RD, Andrascik R, Carty DG, Colvard EM, Ewing R, Gould WR, Gresswell RE, Mahony DL, Olliff T, Relyea SE. 1990. Annual Project Technical Report for 1989, Fishery and Aquatic Management Program. USFWS, Yellowstone National Park.

Kaeding LR, Boltz GD, Carty DG. 1996. Lake trout discovery in Yellowstone Lake threaten native cutthroat trout. Fisherie, 21:16-20.

Kaplinksi MA. 1991. Geomorphology and geology of Yellowstone Lake, Yellowstone National Park, Wyoming [thesis]. [Flagstaff (AZ)]: Northern Arizona University,

Kawecki TJ, Stearns SC. 1993. The evolution of life histories in spatially heterogeneous environments: optimal reaction norms revisited. Evolutionary Ecology, 7:155-174.

Kerfoot WC. 1974. Egg-size cycle of a cladoceran. Ecology 55:1259-1270.

Kilham SS, Theriot EC. Fritz SC. 1996. Linking planktonic diatoms and climate change in the large lakes of the Yellowstone ecosystem using resource theory. Limnology and Oceanography 41:1052-1062.

Koel TM, Arnold JL, Bigelow P, Doepke PD, Ertel BD, Ruhl ME. 2007. Yellowstone Fisheries and Aquatic Sciences Annual Report for 2006. YCR-2007-04, Yellowstone National Park, National Park Service, Yellowstone Center for Resources.

Koel TM, Arnold JL, Bigelow P, Ertel BD, Mahony DL. 2003. Yellowstone Fisheries and Aquatic Sciences Annual Report for 2002. YCR-NR-2003-02, Yellowstone National
Park, Wyo., National Park Service, Yellowstone Center for Resources.

Koel TM, Bigelow P, Doepke PD, Ertel BD, Mahony DL. 2005. Nonnative lake trout result in Yellowstone cutthroat trout decline and impacts to bears and anglers. Fisheries 30:10-19.

Koel TM, Mahony DL, Kinnan KL, Rasmussen C, Hudson CJ, Murcia S, Kerans BL. 2006. Myxobolus cerebralis in native cutthroat trout of the Yellowstone Lake ecosystem. Journal of Aquatic Animal Health 18:157175 .

Kozlowski J, Uchmanski J. 1987. Optimal individual growth and reproduction in perennial species with indeterminate growth. Evolutionary Ecology 1:214-230.

Kozlowski J, Wiegert RG. 1987. Optimal age and size at maturity in annuals and perennials with determinate growth. Evolutionary Ecology 1:231-244.

Krist AC. 2002. Crayfish induce a defensive shell shape in a freshwater snail. Invertebrate Biology 121:235-242.

Lampert W. 1993. Phenotypic plasticity of the size at 1 st reproduction in Daphnia - the importance of maternal size. Ecology 74:1455-1466.

Larsson P, Dodson S. 1993. Chemical communication in planktonic animals. Archiv Fur Hydrobiologie, 129:129-155.

Lass S, Spaak P. 2003. Chemically induced antipredator defenses in plankton: a review. Hydrobiologia 491:221-239.

Latta LC, Bakelar JW, Knapp RA, Pfrender ME. 2007. Rapid evolution in response to introduced predators II: the contribution of adaptive plasticity. Evolutionary Biology 7.

Law R. 1979. Optimal life histories under agespecific predation. American Naturalist 114:399-417.

Law R. 2007. Fisheries-induced evolution: present status and future directions. Marine Ecology-Progress Series 335:271-277. 
Lockwood JL, Hoopes MF, Marchetti MP. 2007. Invasion Ecology. Malden (MA):Blackwell Publishing.

Loose CJ, Vonelert E, Dawidowicz P. 1993. Chemically-induced diel vertical migration in Daphnia: a new bioassay for kairomones exuded by fish. Archiv Fur Hydrobiologie 126:329-337.

Mellors WK. 1975. Selective predation of ephippial Daphnia and resistance of ephippial eggs to digestion. Ecology 56:974-980.

Michod RE. 1979. Evolution of life histories in response to age-specific mortality factors. American Naturalist 113:531-550.

Munro AR, McMahon TE, Ruzycki JR. 2005. Natural chemical markers identify source and date of introduction of an exotic species: lake trout (Salvelinus namaycush) in Yellowstone Lake. Canadian Journal of Fisheries and Aquatic Sciences 62:79-87.

Neill WE. 1990. Induced vertical migration in copepods as a defense against invertebrate predation. Nature 345:524-526.

Ohman MD, Frost BW, Cohen EB. 1983. Reverse diel vertical migration: an escape from invertebrate predators. Science 220:14041407.

Park K. 2004. Assessment and management of invasive alien predators. Ecology and Society 9 .

Prepas E. 1978. Sugar-frosted Daphnia: improved fixation technique for cladocera. Limnology and Oceanography 23:557-559.

Ramcharan CW, Sprules WG. 1991. Predatorinduced behavioral defense and its ecological consequences for 2 calanoid copepods. Oecologia, 86:276-286.

Reznick D, Endler JA. 1982. The impact of predation on life-history evolution in Trinidadian guppies (Poecilia reticulata). Evolution 36:160-177.

Reznick DA. Bryga J, Endler, JA. 1990. Experimentally induced life-history evolution in a natural population. Nature 346:357-359.
Ruzycki JR, Beauchamp DA, Yule DL. 2003. Effects of introduced lake trout on native cutthroat trout in Yellowstone Lake. Ecological Applications 13:23-37.

Sakai AK, Allendorf FW, Jodie S, Holt JS, Lodge DM, Molofsky J, With KA, Baughman S, Cabin RJ, Cohen JE, Ellstrand NC, McCauley DE, O'Neil P, Parker IM, Thompson JM, Weller SG. 2001. The Population biology of invasive species. Annual Review of Ecology and Systematics, 32:305-332.

Schaffer WM. 1974. Selection for optimal life histories: effects of age structure. Ecology 55:291-303.

Skelly DK, Werner EE. 1990. Behavioral and lifehistorical responses of larval american toads to an odonate predator. Ecology 71:23132322.

Smyly WJP. 1970. Observations on rate of development, longevity and fecundity of Acanthocyclops viridis (Jurine) (Copepoda, Calanoida) in relation to type of prey. Crustaceana 18:21-36.

Stearns SC. 1992. The Evolution of Life Histories. Oxford: Oxford University Press.

Stearns SC, Koella JC. 1986. The evolution of phenotypic plasticity in life-history traits: predictions of reaction norms for age and size at maturity. Evolution 40:893-913.

Stibor H. 1992. Predator induced life-history shifts in a fresh-water cladoceran. Oecologia 92:162165.

Theriot EC, Fritz SC. Gresswell RE. 1997. Longterm limnological data from the larger lakes of Yellowstone National Park, Wyoming, U.S.A. Arctic and Alpine Research 29:304314.

Tollrian R, Harvell CD, editors. 1998. The Ecology and Evolution of Inducible Defenses Princeton (NJ): Princeton University Press.

Tronstad LM, Hall RO, Koel TM. (in press). Impact of declining nutrient transport by Yellowstone cutthroat trout on primary and adjacent habitats. Ecological Monographs. 
Tronstad LM, Hall RO, Koel TM, Gerow KG. (in review). Introduced lake trout produced a four-level trophic cascade in Yellowstone Lake. Transactions of the American Fisheries Society.

Varley JD, Gresswell RE. 1988. Ecology, status, and management of the Yellowstone cutthroat trout. American Fisheries Society Symposium 4:13-24.

von Elert E, Loose CJ. 1996. Predator-induced diel vertical migration in Daphnia: enrichment and preliminary chemical characterization of a kairomone exuded by fish. Journal of Chemical Ecology 22:885-895.

Vonderbrink RH, Vanni MJ. 1993. Demographic and life-history response of the cladoceran Bosmina longirostris to variation in predator abundance. Oecologia 95:70-80.

Weber A, Declerck S. 1997. Phenotypic plasticity of Daphnia life history traits in response to predator kairomones: genetic variability and evolutionary potential. Hydrobiologia 360:89-99.
Williamson CE, Reid JW. 2001. Copepoda. In: Thorp $\mathrm{JH}$, Covich AP, editors. Ecology and Classification of North American Freshwater Invertebrates. San Francisco: Elsevier p.829-899.

Winder M, Schindler DE. 2004. Climate change uncouples trophic interactions in an aquatic ecosystem. Ecology 85: 2100-2106.

Witte F, Goldschmidt T, Goudswaard PC, Ligtvoet W, Vanoijen MJP, Wanink JH. 1992. Species extinction and concomitant ecological changes in Lake Victoria. Netherlands Journal of Zoology 42:214-232.

Woodward IO, White RWG. 1981. Effects of temperature and food on the fecundity and egg development rates of Boeckella symmetrica Sars (Copepoda, Calanoida). Australian Journal of Marine and Freshwater Research 32:997-1002. 